Open Access

\title{
Empowering older adults' informal, self- directed learning: harnessing the potential of online personal learning networks
}

\author{
Dirk Morrison $^{1^{*}}$ (D) and Jessica McCutheon ${ }^{2}$
}

\author{
* Correspondence: dirk.morrison@ \\ usask.ca \\ ${ }^{1}$ Department of Curriculum Studies/ \\ Educational Technology \& Design, \\ College of Education, University of \\ Saskatchewan, 28 Campus Drive, \\ Saskatoon, SK S7N 0X1, Canada \\ Full list of author information is \\ available at the end of the article
}

\begin{abstract}
Information and communication technologies have had an enormous impact on how we live, work, communicate, re-create, and connect with others. However, there is a paucity of research regarding older adult learners' adoption and adaptation of Internetbased tools, techniques, and resources to support their informal, self-directed lifelong learning goals. This research contributes to our understanding of how and why older adults leverage the Internet and social media tools to create, develop, and maintain online personal learning networks (oPLNs) for the purposes of self-directed knowledge acquisition, personal development, and the facilitation of healthy aging.
\end{abstract}

Keywords: Older adults, Informal, self-directed learning, Online/Internet/social media, Online personal learning networks

\section{Introduction}

If one were to ask friends and relatives to estimate how important Internet-based activities are to older adults, the likely responses may be variations of "they don't go online, they don't even know how to use the Internet!" The pervasive stereotype of older adults' disregard of and/or ineptness with "all things Internet" remains, sadly, unchallenged. However, the reality of older adults' use of the Internet is quite different from these commonly held negative perceptions. According to a PEW Research Center Report, older adults (aged 65+) increased their social media usage from 2\% in 2005 to $35 \%$ in 2015 (Perrin, 2015). A more recent PEW Internet \& Technology Report (Anderson \& Perrin, 2017) indicates that technology adoption is climbing among older adults (65+), with nearly $60 \%$ going online and a record number now own smartphones. Specifically, within the 65-69 age groups, $82 \%$ reported using the Internet and 59\% owning smartphones.

Self-directed learning, a central concept in adult learning, states that the locus of control for learning lies within the adult learner (Lowry, 1989 in Cercano, 2008). While the literature regarding older adults' activation of self-directed learning strategies and processes for older adults is "thin," Brocket (1986) identified a relationship between self-directed learner readiness and life satisfaction among older adults, such that older adults who engage in self-directed learning tend to have an improved quality of life. Robertson and Merriam (2005) examined self-directed learning processes of older (75-87), rural adults and found that self-directed learning is initiated when there is an incentive and interest in learning,

(c) The Author(s). 2019 Open Access This article is distributed under the terms of the Creative Commons Attribution 4.0 International License (http://creativecommons.org/licenses/by/4.0/), which permits unrestricted use, distribution, and reproduction in any medium, provided you give appropriate credit to the original author(s) and the source, provide a link to the Creative Commons license, and indicate if changes were made. 
thereby motivating the access of resources. They go on to point out that there is often a "catalyst," namely, another person contributing to the success of their self-directed informal learning. Cercone (2008), outlining characteristics of adult learners relevant to the design of formal online learning environments, provided an overview of andragogy as a core theory, followed by an explication of three nested additional theories, namely, experiential, transformative, and self-directed learning. While there is logically a blending of these outcomes, depending on the learning context and foci, it is the latter which is of most interest here. While of background relevance, these studies did not include any consideration of information and communication technologies (ICT) or accessing the Internet for learning. It was surprising to the authors that there is such a paucity of research specifically focused on older adults' use of these powerful learning tools until very recently (e.g., PEW Reports cited above) given that older adults are often uniquely positioned to learn for intrinsic reasons (e.g., personal interest, love of learning) as opposed to being driven by extrinsic motivators (e.g., formal degrees, work promotions).

Global census data clearly indicate a rapidly growing demographic trend: the percentage of older adults, defined as someone aged 60 and older, will rise in developed countries from 22\% of the population in the year 2010 to 29\% in 2030 (World Economic Forum, 2012). An important consideration for any society facing such demographic shifts will be to identify and understand factors that favorably impact the general health and life satisfaction of older adults (Pike, 2011; Hare, 2014). Maintenance of high cognitive function, sustained social engagement, and the pursuit of meaningful activities are essential factors that contribute to collective social capital and individual mental and social well-being as we age (Rowe \& Kahn, 1997). Lifelong learning, and specifically, informal, self-directed lifelong learning, provides an effective conduit and practical conceptual framework to achieve these essential factors (Field, 2009; Merriam \& Kee, 2014). While evidence exists linking lifelong learning to increases in both human and social capital (Balatti \& Falk, 2002), it is not well understood how older adults use the Internet and social media tools to become more knowledgeable and socially engaged.

This research specifically explores how older adults use the Internet and social media tools to create and maintain online personal learning networks (oPLNs) for lifelong learning purposes, such as self-directed knowledge acquisition, personal transformation, meaning-making, and contributions to facilitating healthy aging and community wellbeing. An objective of the current study was to develop an initial understanding of who are creating oPLNs, what these oPLNs look like, and for what purposes they are used. It is our hope that concrete suggestions for this demographic regarding how they might develop, strengthen, and effectively harness Internet resources and social media tools to support their self-directed lifelong learning goals can be generated.

The foundational theoretical framework and set of concomitant assumptions for this study are grounded in andragogy and self-directed learning. As Merriam (2001) indicates, these two conjoined concepts provide the "pillars" of current adult learning theory. While identifying the field as "a mosaic of theories, models, sets of principles, and explanations" to help us understand adult learning, she claims that the two most important pieces of that "mosaic" are andragogy and self-directed learning. The study presented here, while focused on new and innovative adoptions of ICT for the purposes of activating and engaging older adults' informal self-directed learning, is clearly situated within and draws interpretative strength from Merriam's (2001) conceptual theoretical framework. 
However, while andragogy and self-directed learning, per se, are of core theoretical interest here, it is the notion of heutagogy (Hase \& Kenyon, 2000; Blaschke, 2012; Blaschke \& Hase, 2016) that provides a conceptually robust theoretical "lens" through which a clearer view of the phenomenon under study can be understood.

The term "heutagogy," first coined by Hase and Kenyon (2000), captures the essence of the changing landscape of the twenty-first century learning; it succinctly describes a form of self-directed learning that highlights the skill of learning on one's own but, importantly, also learning with technology; the latter qualifier, it is speculated, promotes increased "learner agency" and a more autonomous, self-directed way of learning (Blaschke, 2012; Blaschke \& Hase, 2016). Heutagogy here is seen as an extension of the already well-established principles of andragogy (Smith, 2002), constructivism (Glaserfeld, 1989), self-directed learning (Caffarella, 1993), and student-centered learning (Hase \& Kenyon, 2000; Blaschke \& Hase, 2016). Additionally, these authors emphasize that learning is an innate human endeavor and is, therefore, an internal process best controlled by the learner (Hase \& Kenyon, 2000). An important tenet of heutagogy centers on the issue of control, specifically, control over the learning process, whereas pedagogy, and andragogy to a lesser extent, are traditionally curricula-driven and instructor-led; heutagogy is touted as a truly learner-centered approach where the learner has total control over the learning process.

The emergence of Web 2.0 technologies, especially social media, as tools for learning, has generated new discussions about heutagogy. Blaschke (2012), citing McLoughlin and Lee (2007), suggests that social media, as applied to learning, is an example of one of the new tools of heutagogy, providing connectivity with others, information discovery, and sharing, as well as personal curation and adaptation of information as required; these are all concrete heutogogical affordances that support self-determined and, in this case, informal learning activities. Heutagogy, as both a conceptual framework and learning strategy, is, therefore, well-suited to meet the needs of older adults' pursuit of informal, self-determined learning endeavors using the twenty-first century technological tools and processes. Heutagogy, then, best fits our exploration and understanding of how these older adults used a variety of information and communication technologies, including Web 2.0 tools, to create and maintain online personal learning networks (oPLNs).

\section{What is an oPLN?}

As part of the requirement to participate in the study, respondents had to have a collection of individuals and/or groups with whom they regularly communicate via the Internet to engage in discussion, exchange information, and/or share resources to informally learn more about a hobby or general interest. In other words, this collection of individuals and/ or groups constitutes their unique, online personal learning network, or "oPLN." It is important to point out that oPLNs in this study are focused on participants' informal, self-directed learning, not non-formal or formal (e.g., degree program (Schwier, Morrison, \& Daniel, 2009)). With this in mind, a range of hobbies and/or interest categories were identified and are included as indicative of informal learning.

\section{Methodology}

The purpose of the study was to document and describe the type of older Canadians who engage in online self-directed learning and gain an understanding of their online 
personal learning networks (oPLNs). This study addresses the following research questions:

- Who engages in online self-directed learning?

- What do oPLNs "look" like for these individuals (i.e., access, type, purpose)?

- How do these individuals use their oPLNs for informal self-directed learning?

- What is the perceived value of self-directed learning in their oPLNs?

A national online survey was conducted with 385 retired older adults. Selection criteria required that respondents have an oPLN, be retired, and be at least 55 years of age or older. Given that the purpose was to explore oPLNs, having an oPLN was a base requirement. Further, retirement status and age were selected because it was believed that older, retired individuals would be intrinsically motivated to engage in self-directed learning, as opposed to younger individuals in the workforce who may be motivated by extrinsic forces (e.g., getting a job or a promotion). Age quotas were set to ensure a mix of respondents across three age groups (i.e., 55-64, 65-74, 75+); this was done to obviate the error of assuming homogeneity of sample characteristics and online behaviors by collapsing the older adults across the range of 55+. Some data were also collected from respondents $(n=260)$ who did not have an oPLN, and comparisons are made between the two groups when possible.

\section{Survey instrument}

The survey, entitled How older adults use personal learning networks to support informal, self-directed learning goals, was developed by the first author and staff at the University of Saskatchewan's Social Sciences Research Laboratories (SSRL) and programmed into the online survey platform Qualtrics. The survey instrument was reviewed by stakeholders (i.e., Saskatchewan Council on Aging professional staff) and university ethical approval was granted. Participants were recruited using ProBit, a Canadian panel company, who provided a representative sample across Canada (based on relative populations of provinces and territories). The survey comprised 52 questions, covering a total of 10 discrete categories, the majority of which focused on discovering the nature of participants' use of their oPLNs to support informal, self-directed learning goals.

\section{Results and discussions}

This section is presented by topic and includes the findings of the survey, as well as a brief discussion of the findings within the context of the existing body of literature on older adults' Internet usage and their informal, self-directed learning.

\section{Who is using oPLNs?}

For the purpose of this survey, oPLNs were defined to the participants as a collection of individuals and/or groups with whom you communicate, via the Internet, to engage in discussion, exchange information, and/or share resources to learn more about a hobby or interest. In total, 385 participants met the qualifying criteria and indicated that have an oPLN. The mean age of the qualifying sample was 69.75 years $(\mathrm{SD}=7.82)$. It should be noted that the age distribution of the sample is not reflective of the age of 
older adults using oPLNs as age quotas artificially distributed the sample evenly across three age groups. Fifty-seven percent of the respondents were male, while $43 \%$ were female. The majority of the sample resided in Ontario $(n=184)$ in a large urban area (i.e., population of greater than 100,$000 ; n=186$ ), had completed either a postgraduate degree $(n=126)$ or post-secondary degree or diploma $(n=127)$, and had an annual household income before taxes of $\$ 60,000$ or greater $(n=204)$. Most of the sample indicated that they had been retired between 5 and 15 years $(47.0 \% ; n=181)$, with $28.8 \%$ $(n=111)$ having been retired for more than 15 years. Prior to retirement, the majority of the sample worked in the areas of education $(n=79 ; 24.4 \%)$, business $(n=67 ; 20.7 \%)$ or "other" ( $n=68 ; 21.0 \%)$.

We were also interested in understanding for what hobbies and/or interest categories people were creating oPLNs. Many interests were cited by only one participant; however, several categories were of interest to a number of participants. The most frequently identified hobbies and/or interest categories included politics/world events/news $(6.8 \%, n=26)$, crafts

$(6.0 \%, n=23)$, and sports $(5.7 \%, n=22)$. All other categories represented the interests of less than $5 \%$ of the sample.

\section{General Internet use}

Before delving into their oPLN usage, a general sense of participants' Internet use was collected. Participants were asked how long they have been using the Internet for personal use and in what Internet-based activities they engage. In terms of length of Internet use, response options included "less than 5 years," "five to less than 10," "10 to less than 15," and "15 years or more." Most participants had been using the Internet for a long time, with $77.4 \%(n=298)$ of respondents indicating they have been using the Internet for more than 15 years. The remainder of the sample indicated that they have been using the Internet for 10 years to less than 15 years $(14.3 \%, n=55)$, 5 years to less than 10 years $(7.0 \%, n=27)$, and less than 5 years $(1.3 \%, n=5)$. A chi-squared analysis showed that there is no relationship between age group (i.e., 22-64, 65-74, 75+) and length of Internet use, $\chi(6)=8.37, p=.212$, suggesting that length of Internet use is not more common among younger retired Canadians than those who are older. General Internet usage information was also collected for older adults who reported that they do not have an oPLN. A $t$ test showed that there was no difference between the two groups on their length of Internet use, $t(643)=.528, p=.598$.

Anderson and Perrin (2017) report that seniors are moving towards more digitally connected lives; Internet use and home broadband adoption among this group have risen substantially with $67 \%$ of seniors using the Internet-a 55-percentage-point increase in just under two decades. While our findings indicate a $10 \%$ higher rate of Internet use (77.4\%), over a 15-year span, this is indicative of the cohort selection (i.e., participants were selected from a pool of potential candidates for the online survey, indicated an interest in ICT). An interesting finding here, however, is that we found no significant difference across age groups; this contrasts the PEW Report (2017) that indicated that seniors aged 65 to 69 are about twice as likely as those aged 80 and older to say they ever go online ( $82 \%$ vs. $44 \%$ ). In a previous study, Zickuhr and Madden (2012) found that $50 \%$ of adults aged 65 and older are online (i.e., using the Internet and/or email). Factors such as household income and education levels can affect adoption rates 
of Internet use by older adults. Anderson and Perrin (2017) indicate that $87 \%$ of seniors with yearly household incomes greater than $\$ 75,000$ have home broadband, while only $27 \%$ of those with annual incomes below $\$ 30,000$ have home access. Moreover, they report that college graduates use technology to a much greater extent than seniors with lower levels of education. Our cohort of participants reported both higher household incomes (only $7.6 \%$ below $\$ 30,000 ; 21 \%$ between $\$ 30,000$ and $\$ 59,999 ; 22.6 \%$ between $\$ 60,000$ and $\$ 89,000$; and, $31 \% \$ 90,000$ or greater) and educational levels $(91.7 \%$ with some post-secondary education and $35.5 \%$ having completed a post-graduate university degree) than the regular population.

Our participants were asked to select from a list of 24 options to indicate which Internetbased tasks or activities they have used within the last 12 months. Almost all participants (99.7\%, $n=384$ ) use the Internet for checking their email. Other common uses included reading news $(86.5 \%, n=333)$, searching for medical or health information $(83.4 \%, n=321)$, browsing for information on goods/services $(79.5 \%, n=306)$, accessing travel information (79.2\%, $n=305)$, visiting government websites $(75.8 \%, n=292)$, e-banking $(75.8 \%, n=292)$, accessing social networking sites $(71.2 \%, n=274)$, and accessing informal learning online $(71.2 \%, n=274)$. The three least common uses included searching for employment $(5.5 \%$, $n=21)$, using learning tools or apps $(22.9 \%, n=88)$, and selling goods or services $(23.9 \%$, $n=92$ ). All other categories received an endorsement from at least a quarter of the sample. The distribution of responses was very similar among respondents who do not have an oPLN, with the exception of the item "Contribute content or participate in online discussion groups." This item was selected by $46.8 \%(n=180)$ of the oPLN sample, while only $16.5 \%$ $(n=43)$ of the non-oPLN sample reported engaging in that activity. This finding is not surprising given that this activity may be directly related to engagement with their oPLNs.

An early study by Trocchia and Janda (2000), examining older adults' online activity reflects the above findings, namely, spending at least $10 \mathrm{~h}$ per week, they seek information that is important to them on a personal level (e.g., banking, medical, and local news information). The researchers point out that, compared to their younger counterparts, older adults tend to possess higher levels of free time. This, in our view, may provide new opportunities to incorporate informal, self-directed learning activities within the general context of their use of Internet tools and resources. An important critique offered by these authors, namely, that "the extant research has primarily focused on descriptive information but fails to address motivations, attitudes, and concerns that influence older adults' Internet usage" (p. 605), is one addressed by our research project. While various informative large-scale reports regarding older adults' Internet and associated ICTs (e.g., tablets and smartphones) remains "generic" by describing general adoption and use; no research, to date, has specifically focused on older adults' use of these tools to enhance their lifelong, informal, and self-directed learning. Questions that were targeted to older adults' use of the Internet for these purposes, and, specifically for the creation and maintenance of oPLNs, discovered almost 50\% reporting engaged activity with others within these networks, sharing and consuming resources, and contributing to their online e-learning communities. While Hill, Benyon-Davies, and Williams (2008) indicate that, generally, older adults are disproportionally less likely to be engaged with the Internet (Mason \& Hacker, 2003) and, thereby, benefit less from such engagement and are at risk from social exclusion (Olphert, et al., 2005). Pointing to a "digital divide" phenomenon, this research, which focused on individuals 
who were specifically selected due to their use of the Internet, painted a very different picture. Our results clearly demonstrate not only the use of Internet resources and tools generally, but also the use of these for the specific purposes of enhancing informal, self-directed learning goals. Continued study of such "adopters" of ICT for learning among older adults is a fruitful and promising research trajectory.

\section{Accessing their oPLNs}

While the survey gathered data regarding older adults' general use of the Internet, the core focus of this research was to specifically explore older adults' use of online tools to create, maintain, and expand their oPLNs for self-directed, informal learning goals. Participants were asked which online tools they use to communicate, exchange ideas, and to share resources with members of their oPLN. Echoing their general Internet use, participants most often communicate with their oPLNs by email $(94.3 \%, n=363)$. While not as common, Facebook was also selected by more than half the participants $(55.3 \%, n=213)$. Other somewhat-used tools included blogs $(24.4 \%, n=94)$, Google+ $(23.4 \%, n=90)$, and video conferencing $(14.0 \%, n=54)$.

While some would not consider "email" as a social media tool per se, we included this category as email can serve multiple functions, not the least of which is a conduit for connecting with others, beyond friends, and family, namely, others within oPLNs. Email can be a very effective and efficient Internet tool to communicate, exchange information, pursue gaps in one's knowledge about one's hobby or interest, and generally provide a sense of interconnection and attachment to those in one's oPLN. With more than half of respondents identifying Facebook ${ }^{\mathrm{mm}}$ as a source for activating and maintaining their oPLNs, this social media tool has potential to open new horizons for connecting with others around individual hobbies and interests (e.g., Facebook Groups). While fewer participants adopted the other social media tools we listed, the fact that an impressive percentage did is promising. In addition, there were, undoubtedly, many other social media tools that we did not include, that older adults could, in fact are used to support their oPLNs. For instance, YouTube ${ }^{\mathrm{TM}}$ was not included in relation to participants' oPLN, but when asked about general Internet usage, 51.7\% of respondents "download or watch movies or video clips online (e.g., YouTube)." This finding suggests that, while not reaching the usage level of email or Facebook, some older adults may use platforms like YouTube or Vimeo to engage with their oPLNs. With new and purpose-targeted apps being developed, a continuous stream of new and tailored social media tools (Kallas, 2018) will provide older adults with more and better tools by which to create and maintain their oPLN-based learning goals.

It was also important to get a clear sense of "time investment" regarding these older adults' use of oPLNs. Information was collected about the duration and frequency that they use oPLNs. For the total duration, respondents could select among options ranging from less than 6 months to 10 years or more. Many respondents $(46.2 \%, n=178)$ indicated that they have been accessing their oPLNs for 10 years or more. The remaining responses included $12.7 \%(n=49)$ for $7-9$ years, $19.0 \%(n=73)$ for $4-6$ years, $12.3 \%(n=51)$ for $1-3$ years, $4.2 \%(n=16)$ for $6-12$ months, and $3.9 \%(n=15)$ for less than 6 months. For the frequency of accessing their oPLNs to learn more about their hobbies and/or interests, responses were quite varied, with respondents selecting 
responses across the entire spectrum of choices. These included 7 days per week $(21.3 \%$, $n=82)$, 5-6 days per week (13.5\%, $n=52)$, 3-4 days per week (20.5\%, $n=79), 1-2$ days per week $(21.8 \%, n=84)$, and less than 1 day per week $(20.0 \%, n=77)$. Most respondents ( $46.2 \%, n=178)$ spend less than $1 \mathrm{~h}$ per day engaged with their oPLNs, with the remaining sample indicating 1 to less than $2 \mathrm{~h}(35.3 \%, n=136), 2$ to less than $3 \mathrm{~h}(13.5 \%, n=52), 3$ to less than $4 \mathrm{~h}(2.3 \%, n=9)$, and more than $4 \mathrm{~h}$ per day $(1.0 \%, n=4)$.

While a number of scholarly contributions address personal learning networks, generally (Wilson, et al., 2007; Wilson, 2008; Siemens, 2014), we could find no research that specifically addressed the online personal learning networks of older adults that provide important details such as time spent accessing and frequency of interacting within these customized and individually relevant digital learning spaces. Within our selected research cohort, we begin to see interesting data that give a "snapshot" of how they use their oPLNs for learning, how much time they spend actively engaging with their oPLNs and the participants within that learning environment.

\section{Purposes of informal learning in the oPLNs}

Another important goal of this research was to explore learners' goals and motivations for using their oPLNs. With respect to their hobbies and interests, respondents were asked, out of a list of five reasons, for what purpose they use their oPLNs. A large majority of respondents indicated that they use their oPLNs most frequently to explore and learn new things $(90.9 \%, n=350)$, followed by to learn from others $(73.0 \%, n=$ 281). The remaining options were much less endorsed to share their knowledge with others $(28.8 \%, n=188)$, to learn by interacting with others $(45.7 \%, n=176)$, and to talk with others about their interests and hobbies $(39.5 \%, n=152)$.

By definition, activity in an oPLN presumes an orientation to reciprocity (Aviv, Erlich \& Ravid, 2005), whereby mutually beneficial exchanges of resources, useful information, helpful advice, etc., take place. It was, therefore, important to explore what type of resources might be shared and used within participants' oPLNs. Respondents were asked about the types of resources they share with others in their oPLNs for learning more about their particular hobby or interest, as well as what resources they access. In both cases, participants share and access websites within their oPLNs more than any other resource. Table 1 includes the frequency of participants who access and share each of the listed resources.

Given that our participants spanned three unique age categories, chi-squared analyses were conducted to examine if sharing or accessing some resources over others differed by age. To account for multiple comparisons, a Bonferroni correction was implemented. Significant values were required to be less than .005 . The analyses revealed that older people $(75+)$ are less likely to access websites through their oPLN, are less likely to share and access photos, and are less likely to access videos. The results also showed that the youngest age group (55-64) are less likely to share their contact information.

While Zickhur and Madden (2012) found that 77\% of adults between 50 and 64 years of age use the Internet, with 53\% over the age of 65 doing so, they report that a mere $34 \%$ over the age of 75 use the Internet. However, a thorough review of the literature found a paucity of research literature that offered any increased granularity within these broad age categories; in addition, none reported details regarding why older adults were using the 
Table 1 Frequency of participants who share and access certain resources within their oPLN, by age group. Chi-squared analyses assessing the relationship between resource access/sharing and age. Significant analyses at the level of $p<.005$ are marked $\left(^{*}\right)$

\begin{tabular}{lllllll}
\hline \multirow{2}{*}{ Resources } & & \multicolumn{2}{l}{ Age group, \% $(n)$} & \multirow{2}{*}{$x^{2}(p)$} \\
\cline { 2 - 5 } & & All ages & $55-64$ & $65-74$ & $75+$ & \\
\hline Websites & Shared & $69(265)$ & $69(89)$ & $73(93)$ & $65(83)$ & $1.82(.402)$ \\
& Accessed & $82(314)$ & $85(110)$ & $88(112)$ & $72(92)$ & $12.17(.002)^{*}$ \\
Text documents & Shared & $58(223)$ & $56(72)$ & $62(79)$ & $56(72)$ & $1.14(.566)$ \\
& Accessed & $66(253)$ & $65(84)$ & $67(86)$ & $65(83)$ & $.187(.911)$ \\
Photos & Shared & $58(222)$ & $71(91)$ & $56(72)$ & $46(59)$ & $15.89(<.001)^{*}$ \\
& Accessed & $66(254)$ & $75(97)$ & $69(88)$ & $54(69)$ & $13.63(.001)^{*}$ \\
Videos & Shared & $27(105)$ & $30(39)$ & $27(35)$ & $24(31)$ & $1.17(.557)$ \\
& Accessed & $48(183)$ & $59(76)$ & $50(64)$ & $34(43)$ & $16.99(<.001)^{*}$ \\
Contact information & Shared & $51(198)$ & $40(51)$ & $57(73)$ & $58(74)$ & $11.00(.004)^{*}$ \\
& Accessed & $45(175)$ & $40(51)$ & $43(55)$ & $54(69)$ & $5.83(.054)$ \\
\hline
\end{tabular}

Internet or how they were using the Internet. It was, therefore, important that we examine these details regarding not simply the "why" (i.e., to learn) but the "how" (to share and consume resources shared by others) of our participants' use of the Internet.

\section{Perceptions of value regarding oPLNs}

In addition to sharing and accessing valuable learning resources, to acquire new knowledge, a critical characteristic of an effective oPLN, or, generally, use of social media for learning (Greenhow, 2011), is that it connects people, all of whom are clustered around a mutual interest. This research asked two questions about factors that may contribute to a sense of online community. Respondents were asked, using a five-point Likert scale ( $1=$ strongly disagree to $5=$ strongly agree $)$, whether some members in their oPLN provide critical support and/or encouragement about their specified hobby and/or interest. Almost all participants agreed $(52.7 \%, n=203)$ or strongly agreed $(25.5 \%, n=98)$ with this statement. A small minority $(16.4 \%, n=63)$ neither agreed nor disagreed. Ten participants disagreed $(2.3 \%)$ or strongly disagreed (.3\%). They were also asked whether they specifically felt a sense of community with other learners in their oPLN. Again, the majority of participants agreed $(55.8 \%, n=215)$ or strongly agreed $(16.9 \%, n=65)$ with this statement. Less than a quarter of the sample neither agreed nor disagreed $(22.6 \%, n=87)$, and very few participants disagreed $(3.4 \%, n=13)$ or strongly disagreed $(.8 \%, n=3)$.

In a study investigating associations between Internet use and sense of community, Sum, Matthews, Pourghasem, and Hughes (2009) found a positive association between a sense of belonging to an online community, sense of community, and well-being. Participants' use of the Internet for communication and information, and the frequency and history of their Internet use, was consistently related to a greater sense of community. In the current study, with $78.2 \%$ agreeing that they received critical support and/ or encouragement in their oPLNs and $72.7 \%$ agreeing that their oPLNs provided a sense of community, it is clear that the majority of participants were receiving value from their active participation in their oPLNs and it is presumed here that this may have had a positive impact on their sense of well-being and connectedness to others. 
Active, self-directed learning also, undoubtedly, has a primary goal of knowledge acquisition. For this purpose, oPLNs may be particularly useful if they have experts as members. Asked to consider other members of their oPLN, respondents were asked using the same five-point Likert agreement scale $(1=$ strongly disagree to $5=$ strongly agree) whether some members provide expert knowledge about their hobby/interest. Most participants agreed $(49.1 \%, n=189)$ or strongly agreed $(36.9 \%, n=142)$. The remainder of the sample neither agreed nor disagreed $(10.9 \%, n=42)$ or disagreed $(2.3 \%$, $n=9$ ). Older adults' use of the Internet for specific knowledge acquisition arenas is varied and often includes health information (Xie, 2009; Harrod, 2011), financial matters, searching for entertainment and general information, and to compensate for decreased mobility as an "adaptive tool" (McMellon \& Schiffman, 2000, p. 139). Given the purposes of participation in an oPLN, it is not surprising that participants identified expert members within their oPLN. After all, participants are pursuing knowledge acquisition regarding their specific hobby and/or interest and having someone more knowledgeable and/or experienced in the relevant content or skill domain (i.e., an expert), present in the oPLN, would be deemed a useful source of learning.

\section{Active learning and self-directedness in oPLNs}

Exploring the phenomena of active learning and self-directedness within the context of older adults' use of oPLNs was an important goal of this research. Participants were asked, using a five-point scale ( $1=$ strongly disagree to $5=$ strongly agree), whether they learn more about their interests and hobbies when they actively seek information online. Most participants agreed $(54.5 \%, n=210)$ or strongly agreed $(32.7 \%, n=126)$. A much smaller proportion of the sample neither agreed nor disagreed $(7.3 \%, n=28)$, disagreed $(2.6 \%, n=10)$, or strongly disagreed $(2.9 \%, n=11)$.

While general findings of older adults, across the age spectrum, are informative for global results, it was decided that separating out the findings within the three age categories (i.e., 55-64, 65-74, and 75+) would be a useful exercise to discover differences within this cohort of older adults regarding their perception of their own active learning and self-directedness. Interestingly, a one-way ANOVA comparing the three age groups found a significant effect of age group, $F(2,382)=5.08, p=.007$. A Tukey post hoc analysis revealed that participants aged $55-64(M=4.26, \mathrm{SD}=.805)$ were significantly more likely than participants in the $75+$ age group $(M=3.93$, SD $=.834)$ to agree that they learn more when actively seeking information online, $p=.005$.

Using a five-point scale ( $1=$ strongly disagree to $5=$ strongly agree), respondents were also asked whether they learn more about their interests and hobbies when they selfdirect their own online learning. Again, the results showed significant agreement with $54.8 \%(n=211)$ of the sample agreeing and $21.6 \%(n=83)$ of the sample strongly agreeing. Greater endorsement was found for the "neither agree nor disagree" option (18.2\%, $n=70)$, but results were similar for those who selected disagree $(2.3 \%, n=9)$ and strongly disagree $(3.1 \%, n=12)$. A one-way ANOVA comparing the three age groups found no significant differences between groups, $F(2,382)=2.91, p=.056$.

Chu and Tsai (2009), examining self-directed readiness (SDR) and Internet self-efficacy (ISE) among adult learners (mean age of 50.7 years) in Taiwan, discovered that SDR plays a major role toward predicting adults' preferences for constructivist learning 
environments. Also, ISE serves as a mediator for the relationship between Internet usage and preferences. Of most interest here is their conclusion greater time spent on the Internet is related to ISE, which subsequently may increase their preferences for Internet-based learning. Cercone (2008), identifies self-directed learning as an important theory to better understand the characteristics of these older adult learners, namely, their independence, willingness to take initiative to activate their learning, persistence in achieving their learning goals, and desire to learn more about their hobby and/or interest area.

\section{General discussion}

Despite stubbornly pernicious stereotypes to the contrary, the results of this national study of 385 retired older adults, across three age cohorts (55-64 years, 65-74 years, $75+$ years), show them to be actively adopting and effectively using the Internet and Web 2.0 social media tools and techniques to create, maintain, and expand their oPLNs. Participants in this study have been long-time users of the Internet, use it for a wide variety of reasons, including to socialize, to connect with others of similar interests, and to enrich and share their knowledge. Not surprisingly, email (e.g., mailing lists, group email) and Facebook were the most commonly cited social media conduits; the heavy reliance on these to create and support their oPLNs may have been due to unfamiliarity with others, perhaps more efficient ICT tools (e.g., YouTube, Vimeo, Twitter), and it appeared that email and Facebook provided the necessary affordances to engage with others in their oPLNs. It was clear that they invested a significant amount of time using their oPLNs to pursue additional learning about their hobbies and/or interests, which spanned an impressive number of categories. They indicated a core motivation to explore and learn new things and to learn from others; they also actively shared their knowledge and a variety of resources with others in their oPLN. It was also clear from the results that the majority of participants felt their oPLNs provided critical support, encouragement, and a sense of community.

Reflecting on the realities of the proportion growth of older adults in Western societies, Doyle and Goldingay (2012) argue that older adults' well-being is intrinsically linked to their social connectedness and inclusion in social networks. Online social networking may have usefulness in order to combat isolation and loneliness. In an online survey of 222 Australians over 55 years of age on Internet use, Sum, Matthews, Hughes, and Campbell (2008) showed that, not surprisingly, respondents used the Internet for communication, seeking information, and commercial purposes; however, what was surprising is that they also found a negative correlation between loneliness and well-being. In other words, greater use of the Internet as a communication tool was associated with lower levels of social loneliness. What is pertinent here, though, is that while they found that greater use of the Internet to find new people was associated with higher levels of emotional loneliness, we would contend that this finding would depend on the core purposes of Internet use. In our study, respondents identified that connecting with others to learn about their hobbies or interests led to not only an increased sense of community but also greater sense of self-efficacy, especially if they were perceived by others as an "expert" in their knowledge domain. While not specifically investigating any correlations between the use of oPLNs and loneliness/sense of well-being, we would hypothesize that this activity would positively correlate with a lowered sense of 
loneliness and a higher sense of well-being. Future research should expand this phenomenon with additional, more current Internet use contexts and tools (e.g., use of social media platforms for learning).

In an early study examining the literature regarding characteristics of leisure activities and leisure satisfaction among older adults, Purcell and Keller (1989) found that reciprocity and control are key characteristics of leisure which helped older adults achieve life satisfaction.

While not the focus of our study, further investigations regarding older adults' use of oPLNs, in which both reciprocity and control are core affordances, would be warranted. Nasi, Rasanen, and Sarpila (2011), in a study examining Internet use and leisure activities amongst seniors in Finland, reported that Internet use is positively correlated with participation in leisure activities. As such, it is critical to examine the role of the Internet and ICTs in the daily lives of older adults.

While the focus of our study was within the context of older retired adults, inferences about the creation, development, and maintenance of oPLNs for informal learners of any age can be made. For example, professional development can take advantage of the model of oPLNs as a process to further enhance workplace learning initiatives. Also, younger people (e.g., those pursuing higher education) could also benefit from oPLNs to supplement and enhance their formal learning goals and needs. In addition, they could use oPLNs for general learning purposes, perhaps expanding on the sophistication and skill set within the parameters of their informal, self-directed learning activities (e.g., learning a second language to enhance their goal of traveling to foreign countries). The potential for additional research examining knowledge acquisition process "synergy" regarding self-regulated motivation to learn, sense of self-efficacy, and the twenty-first century information access and curation skills, to name a few arenas, could have serious implications for and impacts on trajectories of learning theory and research applications to a variety of contexts in which people are focused on learning as a tangible outcome.

Age differences found in this cohort of participants regarding accessing the Internet, general learning online, and activity sharing and consuming resources from their oPLNs are not surprising. Younger participants, in the 55-64 age range are more likely to have been exposed to using the Internet and associated communication tools in the workplace and would, therefore, have a higher comfort level with general computer use; the transitioning of these skills and propensities to use such technologies in service of their own online learning goals and activities makes logical sense. Conversely, within the lifespan of older participants, early exposure to the Internet may have come at a much later stage; adding the associated skill requirement necessary for fully adopting computers to enhance their informal learning goals may be more outside their "comfort zone," with, perhaps, a decreased sense of competence and increased anxiety regarding the use of such ICT tools for learning. The implication here might be that older adults, in the 75+ age range, might benefit from community-based, local, and face-to-face classes that assist in the development of computer use skills necessary for active and rewarding communication with others, in service of their learning goals. In fact, this focus on enhancing connections with others and providing access to the vast resources available within their interest area might be a core motivation strategy to encourage the adoption of such skills and knowledge within the older adult demographic. Innovations such as these, could, in turn, provide researchers with additional opportunities to investigate barriers to participation, with a potential outcome of not only deeper 
understandings regarding this hitherto neglected demographic, but also to test and verify continuing learning strategies that may result in concrete and life-enhancing acquisition of ICT skills and knowledge. In turn, positive outcomes (e.g., connecting with a like-minded community of learners in the arenas of interest) may be realized for individuals and groups. Finally, by identifying oPLNs as the constellation of sites, resource, tools, and communities may assist more older adults to perceive these as a source for extending and enhancing their informal, self-directed learning aspirations and activities.

This research has implications for shifting societal stereotypes regarding older adults and their supposed lack of sophistication using the Internet and social media tools. An important research trajectory would include further exploration of reciprocity as a key motivator for engagement (Schwier, 2007) in communities of informal learning. Adapting research design strategies to the context and application of further investigations of older adults and their use (or not) of the Internet for informal, self-directed learning is one ripe with possibilities. It is the authors' opinion that without some expectation of reciprocity within any community, long-term viability cannot be an expectation; it is a core characteristic of the concept of "community" that members expect to not only "take" resources (e.g., information) but to also "give back" to that community in order for it to thrive and create the very human phenomenon of willing and mutually beneficial exchange. Researchers should consider examining the extent to which older adults participate in "informal" formal education opportunities (e.g., auditing a college course without being enrolled) and how that knowledge is then transmitted through oPLNs.

Finally, while this study was exclusively focused on older adults' use of the Internet to create, maintain, and use their oPLNs to enhance their informal learning interests and hobbies, future research could further investigate this phenomenon within a variety of age cohorts. For example, it would be useful to explore the use of oPLNs within the adult working population, how they might be using their oPLNs to not only enrich their informal learning, but also to enhance their professional development goals. Workplace training strategies could benefit greatly from a deeper understanding regarding how best to use oPLNs for non-formal learning (e.g., workplace learning) to catalog and reward workers and professionals alike in their self-motivated and autonomous efforts to improve their workplace relevant knowledge and skills (e.g., track and record these activities within a "e-portfolio" conceptual framework). Additional explorations, following a similar research methodology as outlined here, could also investigate younger peoples' use of online technologies and software tools to create oPLNs for either their informal learning goals, or those directly relevant to their formal learning contexts (e.g., K-12, higher education) and challenges (e.g., online study groups; topical, content-specific online learning communities, both local and/or geographically dispersed). While some innovative uses of ICT are currently taking place, the explicit harnessing of these oPLNs for pedagogical purposes is surprisingly vacant from both the literature and the classroom.

\section{Limitations and further research}

The findings and recommendation offered here need to be considered in light of the study's limitations, namely that the sample characteristics (e.g., higher socio-economic standing and higher education levels) are not representative of the general population of older adults and, therefore, the findings cannot be generalized. However, unlike similar studies (e.g., Doyle and Goldingay, 2012), this study did provide a range of ages, a 
representative gender balance, and geographic diversity. Therefore, more confidence in the findings can be found given the researchers' attempts to "cast a wide net" to have a more diverse and representative sample. This study's findings are descriptive in nature and future studies would need to provide more in-depth analyses of the purposes and methods for creating and maintaining oPLNs for informal online learning. Researchers should consider using other methodological approaches to explore older adults' oPLNs. For instance, experimental studies could be used to examine how different facets (e.g., open access vs. membership) or platforms are most effective for older adults' informal learning. Social network analysis is another methodological tool that could be powerful in exploring the social aspects of older adults' oPLNs and how they serve to maintain well-being. Also, future research should explore how social connectedness through the use of social media and the Internet, as applied to older adults' informal, self-directed online learning activities, can target marginalized persons (e.g., those with lower household incomes, less educated, etc.). One possible policy solution would be to implement subsidies to provide older adults with technological equipment and broadband access.

Another notable limitation of this study is that a relative "savviness" (as compared to the base population of older adults) in terms of the general use of the Internet for learning purposes was assumed given that the pool of 385 participants was drawn from a database that self-identified as having an oPLN. Also, using the Internet itself to recruit these participants, logically, left out those who are not users of the Internet. There may also have been a "ceiling effect" on questions posted about Internet use, specifically focused as we were on how it is used to enhance informal, self-directed learning, and the utility of oPLNs to facilitate that learning.

While this study was firmly grounded in the assumptions of andragogy (Knowles, 2002; Merriam, 2001) and self-directed learning, Cercone (2008) points to two other theories worth further exploration with older adults learning online, namely experiential (Brookfield, 1995) and transformative learning (Mezirow, 1997). Regarding experiential learning, Merriam and Caffarella (1999) claim that learners need to make connections between their current and past experiences and then make linkages to potential future outcomes. Transformative learning includes a change to one's frame of reference or way of seeing the world (Mezirow, 1997); while perhaps a lofty goal in relation to this study, further studies could investigate the transformative experiences of older adults' active engagement with resources, processes, and other people while pursuing their informal, self-directed learning online. FinallyMcMellon and Shiffman, 2000suggest "continuation theory" as a possible explanation as to why some older adults go online. The theory proposes that "as older adults age, they make adaptive choices to maintain the internal and external structures of their physical, psychological, and social environments" (p. 139). Regarding the latter two structures, our study provided a glimpse into how older adults use their oPLNs to not only maintain, but also to enrich these that may otherwise have been limited by the effects of aging.

\section{Conclusion}

Importantly, the findings of this study have deepened our understanding of how some Canadian older adults have adopted and adapted to an amazing array of Internet and social media tools and techniques to support and enhance their informal, self-directed learning. However, while significant in its unique focus on older adults and their use of the Internet to create and use oPLNs to enrich their motivation to learn, this study is 
only the "tip of the iceberg" of what we can learn about this phenomenon. Further research is necessary to "map the territory" of older adults' use of ICT more completely. Finally, two concrete suggestions relevant to this demographic regarding how we might support the development, strengthening, and effective harnessing of Internet resources and social media tools to support self-directed lifelong learning goals include (1) supporting local initiatives whose aim it is to enhance older adults' skills and knowledge of using the Internet for learning and (2) ferret out preconceived negative notions we collectively might have about older adults and their propensities and abilities to use ICT-based tools. The goal of these suggestions is to empower older adults to embrace and use the twenty-first century communication and knowledge creation tools afforded by the adoption and integration of ICT into their lived lives, thereby facilitating connection with others and creating learning opportunities.

Abbreviations

oPLNs: Online personal learning networks; SSRL: Social Sciences Research Laboratories

\section{Acknowledgements}

The authors acknowledge the assistance of professional research staff at the Social Sciences Research Laboratories, University of Saskatchewan.

\section{Authors' contributions}

DM is the first author and contributed $60 \%$ of the study. JM is the second author and contributed $40 \%$ of the study. Both authors read and approved the final manuscript.

\section{Authors' information}

Dr. Dirk Morrison is an Associate Professor and Graduate Chair in the Department of Curriculum Studies and the Graduate Program in Educational Technology and Design; he has research interests in the following areas: learning design; history and philosophy of EdTech; ICT in society; formal, informal, and non-formal e-learning; and Al applications in education.

Dr. Jessica McCutcheon is the Survey Research Manager and Specialist, knowledgeable in both quantitative and qualitative methodologies and analysis techniques; she recently completed her Ph.D. at the University of Saskatchewan in Applied Social Psychology.

\section{Funding}

This research was supported and funded by the Canadian Social Sciences and Humanities Research Council (SSHRC), Insight Development Grant (IDG), Grant \#: 430-2015-00381.

\section{Availability of data and materials}

Upon request, the authors are willing to share data and related materials with other researchers.

\section{Competing interests}

The authors declare that they have no competing interests.

\section{Author details}

'Department of Curriculum Studies/Educational Technology \& Design, College of Education, University of Saskatchewan, 28 Campus Drive, Saskatoon, SK S7N 0X1, Canada. ${ }^{2}$ Social Sciences Research Laboratories, University of Saskatchewan, Room 260 Arts Building, 9 Campus Drive, Saskatoon, SK S7N 5A5, Canada.

Received: 2 March 2019 Accepted: 26 July 2019

Published online: 22 August 2019

\section{References}

Anderson, M. A., \& Perrin, A. (2017). Tech adoption climbs among older adults. PEW Research Centre, Internet \& Technology Report, Retrieved Sept. 23, 2018 from: http:/www.pewinternet.org/2017/05/17/tech-adoption-climbs-among-older-adults/ Aviv, R., Erlich, Z., \& Ravid, G. (2005). Reciprocity analysis of online learning. Journal of Asynchronous Learning Networks, 9(1), 3-13. Balatti, J., \& Falk, I. (2002). Socioeconomic contributions of adult learning to community: a social capital perspective. Adult Education Quarterly, 52(4), 281-298.

Blanschke, L. (2012). Heutagogy and lifelong learning: A review of heutagogical practice and self-determined learning. International Review of Research in Open and Distance Learning, 13(1), pp. 56-71.

Blaschke, L., \& Hase, S. (2016). Heutagogy: A Holistic Framework for Creating Twenty-First-Century Self-determined Learners. In M. M. Begoña Gros, Kinshuk (Ed.), The Future of Ubiquitous Learning, pp. 25-40. Springer Berlin Heidelberg. https://doi. org/10.1007/978-3-662-47724-3_2.

Cercone, K. (2008). Characteristics of adult learners with implications for online learning design. AACE Journal, 16(2), 137-159. Chesapeake, VA: Association for the Advancement of Computing in Education (AACE). Retrieved February 4, 2019 from http://www.learntechlib.org/primary/p/24286/. 
Chu, R. J. C., \& Tsai, C. C. (2009). Self-directed learning readiness, Internet self-efficacy and preferences towards constructivist Internet-based learning environments among higher-aged adults. Journal of Computer Assisted Learning, 25(5), 489-501.

Doyle, C., \& Goldingay, S. (2012). The rise of the 'silver surfer': online social networking and social inclusion for older adults. Journal of Social Inclusion, 3(2), 41-54.

Greenhow, C. (2011). Online social networks and learning. On the Horizon, 19(1), 4-12. https://doi.org/10.1108/10748121111107663.

Glaserfeld, E. von (1989). Cognition, construction of knowledge, and teaching. Synthese, 80(1), pp. 121-140.

Hare, E. (2014). Retirement wave could mean golden years for workers. Retrieved July 16, 2014 from: http://dolanecon. blogspot.ca/2011/01/could-federal-spending-be-capped-

Harrod, M. (2011). "I have to keep going": why some older adults are using the Internet for health information. Ageing International, 36(2), 283-294.

Hase, S., \& Kenyon, C. (2000). From Andragogy to Heutagogy. ultiBASE. Retrieved from http//ultibase.rmit.edu.au/Articles/dec00/hase2.htm.

Kallas, P. (2018). Top 15 most popular social media sites and apps. Dreamgrow: Content Marketing \& Social Media Information Retrieved Nov. 12, 2018 from: http://www.dreamgrow.com/top-15-most-popular-social-networking-sites/.

Lowry, C.M. (1989). Supporting and facilitating self-directed learning. (ERIC Document Reproduction Service No. ED312 457). Retrieved March 21, 2018, from http:/www.ntlf.com/html/lib/bib/89dig.htm

0 era. In ASCILITE 2007: ICT: Providing choices for learners and learning, 24th Annual Conference of the Australasian Society for Computers in Learning in Tertiary Education, pp. 664-675. http:/www.ascilite.org.au/conferences/singapore07/procs/mcloughlin.pdf.

Olphert, C. W., Damaodaran, L. \& May, A. J. (2005). Towards digital inclusion-engaging older people in the 'digital world' Accessible Design in the Digital World Conference. Retrieved from: https:/www.researchgate.net/publication/22862372 7_Towards_digital_inclusionengaging_older_people_in_the_\%27digital_world\%27

Mason, S. M. \& Hacker, K. L. (2003). Applying communication theory to digital resarch. Society 1(5), pp. 40-55.

McMellon, C. A., \& Shiffman, L. G. (2000). Cybersenior mobility: why some older consumes may be adopting the Internet. Advances in Consumer Research, 27, 139-144.

Merriam, S. B. (2001). Andragogy and self-directed learning: pillars of adult learning theory.In: New Directions for Adult and Continuing Education, 89, Spring, 2001.

Merriam, S. B., \& Caffarella, R. S. (1999). Learning in adulthood (2nd ed.). San Francisco: Jossey-Bass.

Merriam, S. B., \& Kee, Y. (2014). Promoting community well-being: the case for lifelong learning for older adults. Adult Education Quarterly, 64(2), 128-144.

Mezirow, J. (1997). Transformative learning. New Directions for Adult and Continuing Education, 74, 5-12.

Nasi, M., Rasanen, P. \& Sarpila, O. (2011). ICT activity in later life: Internet use and leisure activities amongst senior citizens in Finland. Eur. J. Ageing, 9(2), 169-176.

Perrin, A. (2015). Social media usage: 2005-2015. Pew Research Center, Internet, Science \& Tech. Retrieved November, 2016 from: http://www.pewinternet.org/2015/10/08/social-networking-usage-2005-2015/.

Pike, P. D. (2011). Using technology to engage third-age (retired) leisure learners: a case study of a third-age MIDI piano ensemble. International Journal of Music Education, 29(2), 116-123.

Purcell, R. Z., \& Keller, J. M. (1989). Characteristics of leisure activities which may lead to leisure satisfaction among older adults. Activities, Adaptation, \& Aging, 13(4), 17-30. https://doi.org/10.1300/J016v13n04_03.

Roberston, D. N., \& Merriam, S. B. (2005). The self-directed learning process of older, rural adults. Adult Education Quarterly, 55(4), $269-287$.

Rowe, J. W., \& Kahn, R. L. (1997). Successful aging. The Gerontologist, 37(4), 433-440.

Schwier, R. A. (2007). A typology of catalysts, emphases and elements of virtual learning communities. In R. Luppicini (Ed.), Trends in Distance Education: A Focus on Communities of Learning (pp. 17-40). Greenwich, CT: Information Age Publishing.

Schwier, R. A., Morrison, D., \& Daniel, B. (2009). A comparison of formal and non-formal virtual learning communities. In V. Uskov (Ed.), Proceedings the Seventh IASTED International Conference on Web-Based Education, Innsbruck, Austria (pp. 321326). Calgary, AB: International Association of Science and Technology for Educational Development \& ACTA Press.

Siemens, G. (2014). Connectivism: a learning theory for the digital age. e-Learning Library, pp. 1-8. Retrieved Sept. 24, 2018 from: http://www.itdl.org/journal/jan_05/article01.htm, 2014-02-10

Smith, M. K. (2002). 'Malcom Knowles, informal adult education, self-direction and andragogy. The Encyclopedia of Informal Education, INFED, Retrieved Nov. 12, 2018 from http://www.infed.org/thinkers/et-knowl.htm

Sum, S., Matthews, R. M., Pourghasem, M., \& Hughes, I. (2009). Internet use as a predictor of sense of community in older people. CyberPsychology \& Behaviour, 12(2), 121-129.

Wilson, S. (2008). Patterns of personal learning environments. Journal of Interactive Learning Environments, 16(1), 17-34.

Wilson, S., Liber, O., Johnson, M., Beauvoir, P., Shaples, P. \& Milligan, C. (2007). Personal learning environments: challenging the dominant design of educational systems. Journal of e-Learning and Knowledge Society, 3(2), pp. 27-38.

World Economic Forum. (2012). Global population ageing: peril or promise? Retrieved November 28, 2014, from: http://www. who.int/ageing/publications/exploding_myths/en/index.html

Xie, B. (2009). Older adults' health information wants in the Internet age: implications for patient-provider relationships. Journal of Health Communications: International Perspectives, 14(6), 510-524.

Zickuhr, K. \& Madden, M. (2012). Older adults and internet use. Pew Research Center's Internet \& American Life Project. Retrieved Oct. 12 from: http://www.sainetz.at/dokumente/studien/Older_adults_and_internet_use_2012.pdf

\section{Publisher's Note}

Springer Nature remains neutral with regard to jurisdictional claims in published maps and institutional affiliations. 